\title{
Marital Domestic Violence and Maternal Health in Nigeria: Evidence from the Demographic and Health Survey
}

\author{
Atsiya Pius, Amos $^{1 *} \quad$ Maimona M. Hauwa'u $(\mathrm{PhD})^{2} \quad$ Atsiya Godiya, Pius $(\mathrm{PhD})^{2}$ \\ 1.Department of Economics and Related Studies, University of York, United Kingdom \\ 2.Center for Gender Studies, Nasarawa State University, Keffi-Nigeria
}

\begin{abstract}
There is increasing evidence that the non-cooperative models describe household structures in developing countries more succinctly compared with the unitary model. Domestic violence against women, which is pervasive in Nigeria even though likely to be under-reported, will need to be understood within the framework of noncooperative relationship between couples. In this study, we identify factors of domestic violence against women within couples who were currently in marital or cohabiting partnerships. Also, we investigate whether domestic violence influences the decision of women to terminate pregnancies. We use data from the 2018 Nigeria Demographic and Health Survey (NDHS). Multivariate logistic regressions were used to model the predictors of domestic violence, and its influence on the decision to terminate pregnancies among married women. Of the 8,910 married women interviewed for domestic violence, $35.33 \%$ had ever experienced a form of domestic violence. We discover that women: with higher education, that is not poor, and resides in urban areas have $44 \%, 18 \%$ and $15 \%$ reductions in the odds of experience domestic violence respectively. On the other hand, women who are employed, own land, having husbands/partners that are employed in the agricultural sector, and drink alcohol have 1.16, 1.2, 2.07, and 2.8 times increased odds of experiencing domestic violence accordingly. Also, we uncover that currently married women experiencing domestic violence have 1.25 times increased odds of terminating pregnancies compared with their counterparts that are not experiencing domestic violence. Effectively, poverty, low levels of education, residing in rural areas, drinking habit of husbands/partners, employment, marital capital, and land ownership status of women are risk factors of domestic violence against married women in Nigeria but can be affected by policies and programmes. Importantly, public actions to contain domestic violence in order to improve maternal health should be implemented in the context of the dynamics of a non-cooperative relationship existing between married couples.
\end{abstract}

Keywords: Non-cooperative Household Model; Domestic Violence; Maternal Health; Nigeria

JEL Classification: D13; J12; I14.

DOI: $10.7176 /$ RHSS/11-2-07

Publication date: January $31^{\text {st }} 2021$

\section{Introduction}

Household structure can be modelled along two paths: unitary models and collective models. In a generic sense, unitary models specify a homogeneous utility function which is maximised subject to a pooled income constraint. In contrast, collective models and in particular, the non-cooperative models strand, assume independence of household members in terms of preferences and decisions making on production and consumption given that resources are not pooled. A detailed review of these models has been done elsewhere (Atsiya, Pius, and Agbutu, 2019). There is rising evidence about non-cooperative models, as opposed to unitary models, being the best reach models in describing households in developing countries. For example, Doss, (2001) validated the assertion of heterogeneous preferences and varied decision making on resource allocation based on transitory income amongst households in Ghana. Studies with similar findings include Udry (1996); Duflo and Udry, 2004; Rangel and Thomas, 2005; Akresh, 2008; and Bobonis, 2009). Specifically, individuals with decision making powers within households were found to operate as autonomous sub-economies with differing preferences. This appears to provide the framework for a model of marriage that is not solely altruistic in nature and can be characterised by domestic violence in developing countries. Said differently, violence against women in these countries can be associated with the institution of marriage-which is used for the negotiation and expression of gender roles and relations that are in support of patriarchy.

Domestic violence, which is described as the intentional use of physical force or power, threatened or actual, against oneself, another person, or against a group or community that either results in or has a high likelihood of resulting in injury or death (Krug, Mercy, Dahlberg, \&Zwi, 2002) could have severe effect on women in several ways. It can affect their physical, mental, sexual, and reproductive health as well as the health of their children (Garcia-Moreno, et al., 2006; WHO, 2013). More precisely, domestic violence may result in unwanted pregnancies, increase the risk of sexually transmitted infections among women, and during pregnancy, it can increase the risks of miscarriage, preterm labour, foetal distress, and low birth weight (Heise, Ellsberg and Gottenmoeller, 2002; Valladares, et al., 2002). Importantly, at the macroeconomic level, domestic violence is likely to prevent the expansion of women capabilities and can undermine the development progress of a country (Panda and Agarwal, 
2005). This is because, violence or the threat of violence can constrain the choices women make and restrict their participation in development, thus, preventing them from realizing their full potential (ICRW, 2002).

This paper answers the question of what factors are underlying women's risk of marital violence in Nigeria. Additionally, we investigate the research question: Does marital domestic violence increases the likelihood of terminated pregnancies among Nigerian women? Since violence against women is a major public health and human rights problem, empirically identifying the risk factors, and exploring the pathways, through which such factors may influence women's vulnerability in marriage will be crucial in designing policies and programmes. More so, since exiting marriage through divorce is considered as a social stigma across the major ethnic groups in Nigeria, identifying the underlying factors of domestic violence and its effect on pregnancy terminations will be crucial in improving maternal health.

The contribution of this study to the domestic violence literature is twofold. First, it addresses the issue of domestic violence in a multicultural setting using a very recent individual level data released-the 2018 Nigeria Demographic Health Survey (NDHS). Nigeria is a multi-ethnic country with over 250 ethnic groups with divergent norms and cultural values. Cultures in Nigeria perceive domestic violence differently. For instance, while wife beating in the Tiv culture is considered as a show of affection (Oyediran and Isiugo-Abaniher, 2005; Odimegwu, 2001), Igbo women condone and are complacent with intimate partner violence, perceiving it as cultural and religious norms (Ilika, 2005). In general, the major ethnic groups in Nigeria-Yoruba, Igbo and Hausa-tend to support domestic violence (Kritz and Makinwa-Adebusoye, 2006), but disproportionately. Also, existent criminal provisions by the Nigerian law to curb domestic violence appear to be inconsistent. For instance, while the Penal Code which applies in the 19 Northern states, including the Federal Capital territory, specifically Section 55(1)(d) did not consider the chastisement of a wife by her husband as criminal provided it is supported by native law and custom and it does not cause grievous hurt. The Criminal Code which applies to the 17 southern states, on the other hand, does not refer to domestic violence at all (Aduba et al in Chikwanha, 2009; Ojigho, 2009). To address this endogeneity issue, we control for ethnicity in our model specification. In the Nigeria Demographic Health Survey (NDHS) 2018, women were distributed into eleven ethnic groups: Ekoi, Fulani, Hausa, Ibibio, Igala, Igbo, Ijaw/Izon, Kanuri/Beriberi, Tiv, Yoruba, and Other. More precisely, we use a specification that controls for ethnicity fixed-effect to tease out less biased probability values of predictors. Second, this study delineates the pathways through which the predictors it uncovers influence domestic violence. Specifically, it identifies in the literature potential pathways that risk factors can affect domestic violence.

Domestic violence in Nigeria can be explained using the Patriarchal Theory of Family violence and the Exchange Theory (Levinson, 1989). The Patriarchal Theory suggests that, males, historically have dominated societies with women treated as their possessions. In such societies, there are patriarchal norms that support men's ability to control their wives and justify their use of violence to do so. On the other hand, the Exchange Theory suggests that domestic violence is low in societies where the costs to perpetrators are low because of inadequate social controls and the emphasis on male aggressiveness that tend to encourage violence.

The literature identifies a variety of risk factors which may influence domestic violence within a marriage. In theory, women with more education are likely to find better jobs, receive a higher wage rate, be financially independent, and face a better marriage market with higher reservation utilities (Hidrobo and Fernald, 2013). Put differently, they are more likely to have better out-of-marriage options and this can affect their level of exposure to domestic violence. However, awareness of women might increase with more education and this may be a source of stress for the husband who may resort to violence if his autonomy is challenged. The effect of women's employment on domestic violence in the literature is ambiguous (Bhattacharyya, Bedi, and Chhachhi, 2011). While an increase in the household economic resources attributable to the employment status of the husband is expected to reduce economic stress and consequently reduction in domestic violence as suggested by the Resource Theory (Goode, 1971), an increase in household economic resources attributable to the wife may introduce additional tension and struggle for power within the household. This may occur if the husband seeks to control the additional income in order to protect his status as the patriarchal bread winner of the family which may result in violence. In other words, the Resource Theory suggests that husbands are more likely to resort to violence if they contribute less resources to a relationship or when they lack education and job prestige.

Farmer and Tiefenthaler (1997) consider marital capital as a predictor of domestic violence. They represented marital capital with the number of children in a marital relationship but suggested that the effect of children on the level of violence may be ambiguous. In effect, marital capital offers the woman utility (positive or negative) only within a marriage contract. Women are likely to condole domestic violence if they believe that their children are better off in an intact family. On the other hand, if a woman believes that domestic violence has adverse effect on her children, her marital utility is likely to fall below the reservation utility (minimum utility level required to guarantee the marriage contract), and this might reduce violence. Also, a woman's ties to her marital relationship are likely to be stronger if the children are younger (under-five years) and this may increase the level of domestic violence. Relative earning status between spouses could be a risk factor for domestic violence. To be explicit, the marital dependency theory suggests that being economically dependent on a male partner increases women's risks 
of abuse, since it makes then less likely or able to exit the relationship (Vyas and Watts, 2009). Thus, the level of violence is likely to be lower for women who earn the same or higher than their husband/partner. This is because, the value of transfer to such women is likely is to be lower relative to women that earn less than their husbands/partners. Consequently, husbands are more likely to institute violence in a marital relationship that involves higher value of transfer to the woman. Additionally, the bargaining power of women with the same or higher earning status compared to their husbands/partner is expected to be higher relative to women with lower earning status.

The association between women's ownership of property (land and house) and domestic violence exist in the literature (Panda and Agarwal, 2005). In particular, women's land or house ownership in agrarian societies indicates their strength of a fall-back position and possibly tangible exit option (Agarwal, 1997), and this can influence the extent of their exposure to domestic violence. Indeed, land ownership can engender women's economic empowerment and sense of economic security and consequently, reduce their tolerance of violence (Agarwal, 1994; Panda and Agarwal, 2005). Husbands'excessive alcohol consumption can influence their resort to domestic violence (WHO, 2009; Boden, Fergusson, Horwood, 2012; Tumwesigye, Kyomuhendo, Greenfield, and Wanyenze, 2012). Alcohol can have direct effects on physical and cognitive performances, impairing judgment, reducing self-control and the ability to recognize signs of danger and consequently contributing to violence (Gebara, et al., 2015). Alcohol is used as a reason to commit violence based on the cultural belief that it causes aggression (WHO, 2009).

Contributions in the public health and feminist economics literature, closer to this work in scope and methodologies, also consistently find the following characteristics to be associated with domestic violence: higher women education, working husbands and wives, fewer children, alcohol drinking husbands, and younger women age (Barnawa, 2017; Adjah\&Agbemafle, 2016; Rapp, Zoch, Khan, et al., 2012; Bates, Schuler, Islam \& Islam, 2004). Tumwesigye, Kyomuhendo, Greenfield and Wanyenze (2012) showed that women whose partners got drunk often were six times more likely to report physical intimate partner violence compared to those whose partners never drank alcohol. Studying Bhattacharyya, Bedi, and Chhachhi, (2011) showed that women's work status and property ownership are associated with reductions in violence. Finally, in a recent study on 10 developing countries that investigated key individual and couple characteristics associated with experiencing physical or sexual intimate partner violence, women's education was discovered to be protective in some countries but increases the risk of intimate partner violence in one country. Also, husband/partner characteristics were not consistently associated with women's experience of violence. In particular, while men working in agriculture are protective in Bangladesh and Malawi, it is a risk factor of violence against women in Kenya and Zimbabwe (Hindin, Kishor and Ansara, 2008). The above findings provide hints that individual/couple characteristics might have ambiguous effects on intimate partner violence.

None of the previous studies, however, explicitly controls for the potential endogeneity of domestic violence supported by culture.

In the next section we describe the data and statistical technique. Section 3 presents the results and discussion of findings. The last section concludes.

\section{Method \\ 2.1 Data}

We use the 2018 Nigerian Demographic and Health Survey (NDHS) dataset to identify the predictors of domestic violence among married women. This is because the NDHS has information on different forms of domestic violence, as well as, a list of possible covariates, permitting robust investigation of the likely determinants of domestic violence. Our sample is limited to currently married women because violence against women appears to be more associated with the marriage institution which has cultural norms that tends to support domestic violence in Nigeria.

The NDHS is a national sample survey that provides information on fertility levels, marriage, fertility preferences, awareness and the use of family planning methods, child feeding practices, nutritional status of women and children, adult and childhood mortality, awareness and attitudes regarding HIV/AIDS, female genital mutilation, and domestic violence. The NDHS data were sourced through a stratified two-stage cluster sample design using a sampling frame that consists of a list of 1,400 enumeration areas from the 2006 National Population Census for the first stage. In the second stage, a representative sample of 41,821 households was selected for the survey. Specifically, we use the women file for this study with De facto currently married woman interviewed as the unit of analysis.

\subsection{Variables}

Dependent Variable (Domestic violence)

In this study, we consider all forms of domestic violence inflicted on a woman including physical, emotional, and sexual violence. Physical violence, defined as hitting, slapping, punching, choking, pushing, and other types of 
contact that result in physical injury to the victim (Saltzman, Fanslow, McMahon, \& Shelley, 2002) was measured using questions in the NDHS such as: Did your (last) husband/partner ever i. push you, shake you, or throw something at you? ii. Slap you? iii. Twist your arm or pull your hair iv. Punch you with his fist or with something that could hurt you? v. kick you, drag you, or beat you up? vi. try to choke you or burn you on purpose? vii. threaten or attach you with a knife, gun, or other weapon? Emotional violence as defined by Saltzman, Fanslow, McMahon, \& Shelley involve threatening, intimidation, undermining the victim's self-worth or self-esteem, or controlling the victim's freedom. In the NDHS, emotional violence is measured by asking women if their (last) husband/partner ever: i. Said or did something to humiliate them in front of others? ii. Threatened to hurt or harm you or someone close to you? iii. Insulted you or made you feel bad about yourself? Finally, sexual violence defined as the use of force to obtain unwanted, unsafe, or degrading sexual activity (Saltzman, Fanslow, McMahon, \& Shelley, 2002) is measured in the NDHS using two questions. Women were asked if their (last) husbands/partner ever i. physically force to have sexual intercourse even when they did not want to? ii. Forced to perform any sexual acts they did not want to?

In effect, physical violence is indicated if a woman answers "yes $=1$ " to any of the above related questions on physical violence and zero otherwise. In similar pattern, emotional violence and sexual violence were indicated if a woman answers "yes $=1$ " to any of the questions related to the types of violence and zero otherwise. We constructed a composite index of domestic violence by combining the three types of violence and a code of " 1 " assigned if any type of violence is indicated with zero otherwise.

\section{Key Independent variables}

We investigate the roles of individual/couple characteristics in predicting domestic violence including education, employment status, property ownership status, marital capital, earning and alcohol consumption.In this study, we measure women education using the four levels of educational attainment: no education (reference category), primary, secondary and higher education. Employment status of women is measured as a binary variable: (i) No employment $=0$ (ii) Employed=1. In contrast, we categorised husband employment into: (i) No employment=1 (ii) Employed=2 (iii) Employed in Agriculture=3. Marital capital was measured using the number of living children in a marital relationship. We measure the earning status of a woman using the survey question whether "a respondent earns more than husband/partner". We assigned 1=wife earns less than husband and $0=$ =wife earns more/the same as the husband. Land ownership status is used as a proxy for property ownership. It is measured as a binary variable: (i) No land $=0$ (ii) Land Own $=1$. Whether a husband uses alcohol or not is measured as: (i) No Alcohol=0 (ii) Alcohol=1. We measure poverty using the wealth index. We dichotomized the wealth quintiles into: (i) Poor $=0$ (poorest and poorer quintiles) (ii) Not Poor=1 (middle, richer and richest quintiles). Said differently, population at the lower end of the wealth index is identified as poor and the population at the upper end as nonpoor or wealthy. Effectively, the wealth index variable in the NDHS can provide a less spurious effect of poverty on domestic violence because of its cross-cultural attribute-all the wealth index components are defined similarly across all the different ethnic groups consisting our sample making it comparable. Finally, we include other individual characteristics such as age, time lapse since last intercourse, religion, and locality of residence. The variables are given in Table 1.

\subsection{Statistical Method}

Two phases of analyses were conducted to answer the question of what are the factors that influence domestic violence among married women in Nigeria. First, we report the distribution of the variables (categorical) variables as frequency counts and test series of associations using the chi-square or fisher's exact test. Precisely, chi-square tests were performed to examine the bivariate association between domestic violence and its predictors. Second, multivariate logistic regression models were used to examine associations between domestic violence and the list of independent variables mentioned elsewhere. Rationale for the inclusion of the independent variables into the model is based on the literature review provided in the introduction and their being significant at alpha 5\% from the bivariate analysis. To further explore the effect of domestic violence on terminated pregnancies (as a proxy for maternal health), we performed additional logistic regression analyses, which examined the relationship between terminated pregnancies and domestic violence as well as other key covariates including poverty, women health autonomy, education, age, employment, parity, locality, and marital capital. We check for multicollinearity using the variance inflation factor. This was done to ensure that none of the predictor variables in the models were highly associated with each other. Data were analysed using stata/MP 16.0 and all statistical tests were two tailed and a $p<0.05$ was considered statistically significant.

\subsection{Results}

Sample Characteristics

Of the 28,888 women currently married, 8,910 women were eligible for the domestic violence module and these constitute the sample size for our analysis. While $32.4 \%$ of the sample had ever experienced at least one form of 
domestic violence, the most frequently reported form of violence is emotional violence $(30.1 \%)$, followed by physical $(8.11 \%)$ and sexual (6.85\%). Majority of the currently married women that had ever experience at least one form of violence are within the age bracket of 26-35years (43.78\%). In other words, younger (15-25 years) and older women (36-49 years) are less likely to experience or report domestic violence (See Table 1). However, a weak bivariate association between women age and domestic violence is apparent as indicated by the p-value of the Pearson chi-square test $(\mathrm{p}=0.084)$. For women who had experience a form of domestic violence, those without any basic formal education are in the majority (37.6\%). In contrast, 59.65\% of who had experience domestic violence had husbands with at least basic primary education. Husbands' education appears to be protective at higher levels $(12.39 \%)$. Also, majority of women that are employed $(69.12 \%)$ did not experience any form of domestic violence. Similarly, $75 \%$ of women that are employed experience domestic violence. The effect of women employment status on domestic violence appears to be ambiguous. The proportion of women who reported domestic violence and belong to the richest wealth quintile $(13.37 \%)$ is less than the proportion of women in the poorest quintile who had experience domestic violence $(21.44 \%)$. Majority of women that reported violence resides in rural areas $(64.18 \%)$ compared with $35.82 \%$ of their urban counterparts. Also, the proportion of women that reported domestic violence but have no land ownership is about three folds greater $(79.88 \%)$ than those who reported domestic violence and hand land ownership status (20.12\%). Majority of women whose husbands/partners drink alcohol (63.18\%) reported domestic violence. Finally, only $2 \%$ of women whose husbands are unemployed reported domestic violence compared to majority of women whose husband are either employed in a skilled occupation or agriculture (98\%).

\section{Factors of Domestic Violence against Women in Nigeria.}

Table 2 presents result of the predictors of domestic violence against currently married women in Nigeria. We uncover that attaining higher levels of education, residing in urban area, and not being poor are protective factors against marital domestic violence in Nigeria. On the other hand, partner/husband consumption of alcohol, employment status of couples, women land ownership and marital capital were identified as risk factors of domestic violence. More precisely, women with higher education have $44 \%$ reduction $(\mathrm{OR}=0.56 ; 95 \%$ CI 0.45 to 0.70) in the odds of facing domestic violence in their marriages compared with those without any form of basic education. Similarly, compared with women that are categorized as poor, women that are not poor have about $18 \%$ reduced odds $(\mathrm{OR}=0.82 ; 95 \% \mathrm{CI} 0.73$ to 0.94$)$ of experiencing domestic violence. Also, women residing in urban areas have significantly lower odds $(\mathrm{OR}=0.85 ; 95 \%$ CI 0.76 to 0.95$)$ of experiencing domestic violence compared with their counterparts in rural areas. Further, women whose partners/husbands drink alcohol have 2.8 times $(\mathrm{OR}=2.8 ; 95 \%$ CI 2.44 to 3.12$)$ increased odds of experiencing domestic violence. Additionally, the result from Table 2 suggests that there is elevated likelihood of women experiencing domestic violence if they are employed $(\mathrm{OR}=1.16 ; 95 \%$ CI 1.034 to 1.29$)$, or their partners are employed in skilled occupation $(\mathrm{OR}=1.8 ; 95 \%$ CI 1.29 to 2.49) compared to partners/husbands that are unemployed. When we consider women whose partners/husbands are employed in the agricultural sector compared with women whose husbands are unemployed, they former have 2.1 times $(\mathrm{OR}=2.07 ; 95 \%$ CI 1.49 to 2.88$)$ increased odds of experiencing domestic violence. Finally, we discover that women with land ownership status are more likely to report domestic violence than women without land ownership in Nigeria (OR=1.2; 95\% CI 1.06 to 1.37$)$.

The above findings, on average, are robust to a different specification that controls for ethnicity fixed effects and the result is presented in Table 3. According to the specification, controlling for ethnicity fixed effects (along with the same list of individual/couple variables used in Table 2), women that are not poor have 14\% reduction $(\mathrm{OR}=0.86 ; 95 \%$ CI 0.76 to 0.98$)$ in their odds of experiencing domestic violence. Similar reduction in the odds of experiencing domestic violence exist for women with higher education compared to those without any form of education $(\mathrm{OR}=0.58 ; 95 \%$ CI 0.47 to 0.74$)$, and for older women within the age bracket of 36-49years compared with younger women within the age bracket of 15 -25years (OR=0.86; $95 \%$ CI 0.74 to 0.99$)$. In contrast, results in Table 3 report elevated odds of women experiencing domestic violence if they are employed $(\mathrm{OR}=1.26$; $95 \% \mathrm{CI}$ 1.11 to 1.41$)$, have marital capital $(\mathrm{OR}=1.22 ; 95 \% \mathrm{CI} 1.09$ to 1.35$)$ or own land ( $\mathrm{OR}=1.18 ; 95 \%$ CI 1.03 to 1.35$)$. Also, we discover increased odds of women experiencing domestic violence whose husbands drink alcohol $(\mathrm{OR}=2.79 ; 95 \%$ CI 2.45 to 3.16$)$ and are employed either in a skilled profession $(\mathrm{OR}=1.89 ; 95 \%$ CI 1.36 to 2.63$)$ or in the agricultural sector $(\mathrm{OR}=2.00 ; 95 \% \mathrm{CI} 1.44$ to 2.79$)$.

Domestic Violence and Women's Decision to Terminate Pregnancies in Nigeria.

Findings from Table 4 indicate that, while domestic violence, women health autonomy, higher education, and age are risk factors, employment, higher parity, and having four and below number of under-five children are protective factors of terminated pregnancies among married women in Nigeria. Specifically, currently married women experiencing domestic violence in Nigeria have 1.25 times (OR=1.25; 95\% CI 1.11 to 1.42$)$ increased odds of terminating pregnancies compared with their counterparts that are not experiencing domestic violence. Similarly, women with health autonomy were found to be 1.43 times $(\mathrm{OR}=1.43 ; 95 \%$ CI 1.20 to 1.70$)$ more likely to have 
terminated pregnancies. Also, women with higher education relative to those without formal education have 1.22 times increased odds of terminating pregnancies. Older women (26-35years) were found to have 1.58 times $(\mathrm{OR}=1.58 ; 95 \% \mathrm{CI} 1.32$ to 1.88$)$ increase in the odds of terminated pregnancies, compared with women aged 15 25 years. Indeed, the odds of having terminated pregnancies increases with age. It is 1.79 times $(\mathrm{OR}=1.79 ; 95 \%$ CI 1.42 to 2.17) for women in the age range of 36-49 years compared with younger women (15-25 years). Further, our result in Table 4 suggests that employed women have $14 \%(\mathrm{OR}=0.86 ; 95 \%$ CI 0.73 to 1.09$)$ reduction in the odds of terminated pregnancies, compared with their counterparts that are unemployed. Similar protective effect exists for women with higher parity (total number of children ever given birth to by a woman). Effectively, women with higher parity-parity2-have, on average, $27 \%(\mathrm{OR}=0.73 ; 95 \%$ CI $0.59-1.09)$ reduction in the odds of terminated pregnancies compared with women that have never given birth. Finally, our result indicates that women with number of under-five children below four have $22 \%(\mathrm{OR}=0.78 ; 95 \%$ CI 0.66 to 0.92$)$ reduction in the odds of terminating pregnancies, compared with women that have no children below five years in Nigeria.

\section{Discussion}

Findings from this study indicate that the odds of domestic violence are significantly lower for rich women, with higher education, and resident in urban area. In contrast, women that are: employed, own land, and have marital capital were discovered to have elevated odds of experiencing domestic violence. Similarly, women whose partner/husbands drink alcohol, and are employment either in skilled occupation or agriculture have increased odds of marital domestic violence. For education, the reduced odds of domestic violence were statistically significant only for women with higher level of education. This is because, women with higher education are more likely to find better jobs, earn higher wage, be financially independent and have a higher reservation utility. Such women are more likely to have better out-of-marriage options and can reduce the odds of domestic violence. Hence, higher education is expected to translate into the potential for employment, earnings or greater social status which serves as protection from domestic violence. Also, our finding on the association between education and domestic violence suggest that, on average, husbands/partners are less likely to be stressed with increased awareness of women due to higher education. The promotion of girl child education beyond primary and secondary enrolments by the Nigerian government as well as non-governmental organizations would provide women with potential opportunities to be independent in marriage with favourable exit option.

Further, our finding that poor women are more likely to report domestic violence has support in the literature (Hotaling\& Sugarman, 1990; Jewkes, 2002; Ellsberg, et al., 1999). This is because; women living in impoverished conditions are likely to have partners/husbands with high levels of stress and consequently, more prone to domestic violence than women with wealthy partners/husbands. Hence, women financial empowerment intervention can reduce their risk of domestic violence by increasing their statuses and power in the family. We discover that women residing in rural areas are likely to have increased risk of domestic violence and this can be attributed to certain aspects of rural culture that reinforce patriarchal beliefs which support domestic violence. In other words, a traditional gender role that reinforces male domination is likely to be more emphasized in rural areas. Thus, rural culture tends to support gender inequality more and this reduces women's ability to report domestic violence. There are possible barriers to women escaping violence in rural areas including absence of police and legal justice system, stigma attached to the public disclosure of violence, and financial insecurity and dependency on partners/husbands (Wendt, 2008). Increasing public awareness about domestic violence and its various forms in rural areas will be important in curbing the menace. Awareness about existent law against domestic violence and options for victims appear to be low in rural areas. Creating counselling centres in partnership with religious and traditional leaders across Local Government Areas wards can be vital as support network for rural women.

In this study, we identify employment of women, and their partners/husbands as risk factors of domestic violence. Effectively, our findings indicate that the odds of women experiencing domestic violence increase when they are employed and/or when their partners/husbands are employed. While the effect of women's employment on domestic violence is ambiguous in the literature (Bhattacharyya, Bedi, and Chhachhi, 2011), we expect partners/husbands' employment to be protective against domestic violence in line with Dekeseredy and Schwartz (2002). For women employment, we argue that the positive association is likely to be driven by unemployed partners/husbands who are stressed from being economically excluded and this can contribute to the odds of increased domestic violence. While an increase in the household economic resources attributable to the employment status of the husband is expected to reduce economic stress and consequently reduction in domestic violence, an increase in household economic resources attributable to the wife may introduce additional tension and struggle for power within the household. This may occur if the husband seeks to control the additional income in order to protect his status as the patriarchal bread winner of the family which may result in violence. We explain the elevated odds of domestic violence against women when their partners/husbands are employed using the Marital dependency theory which suggests that being economically dependent on a male partner increases women's risks of abuse, since it makes then less likely or able to exit the relationship (Vyas and Watts, 2009).

Further, we discover that women whose partners/husbands drink alcohol are more likely to report domestic 
violence. This finding has support in the literature (WHO, 2009; Boden, Fergusson, Horwood, 2012; Tumwesigye, Kyomuhendo, Greenfield, and Wanyenze, 2012). In line with Gebara, et al., (2015), we argue that alcohol could have direct effects on physical and cognitive performances, impairing judgment, reducing self-control and the ability to recognize signs of danger and consequently contributing to violence. Husbands are likely to abuse alcohol and use it as a reason to commit violence based on the cultural belief that alcohol causes aggression (WHO, 2009). Our finding on the association between women land ownership and domestic violence appears to be counterintuitive. In theory, women's land or house ownership in agrarian societies should indicate their strength of a fall-back position, tangible exit option and consequently reduces their exposure to domestic violence (Panda and Agarwal, 2005; Agarwal, 1997; Agarwal, 1994; Panda and Agarwal, 2005). Indeed, we expect land ownership status to engender women's economic empowerment and sense of economic security given that land is a crucial source of income generating asset in an agrarian society. It is unclear why women land ownership increases their odds of domestic violence, but a plausible explanation would be the likely stress and subsequent struggle for power created from enhanced status due to women land ownership. In addition, land ownership in many cultures across Nigeria is still considered an exclusive domain of the men (Ajala, 2017), hence women ownership of land is likely to be viewed as a contestation of power.

When we control for ethnicity, except for land ownership status, all the above identified factors retained their statistical significance. In other words, the relationship between domestic violence and the list of identified factors persist even when we controlled for variation in culture, indicating the robustness of predictors of domestic violence against women in Nigeria.

We investigate the relationship between domestic violence and pregnancy outcomes, such as termination of pregnancy and discover that women that experience domestic violence are more likely to terminate their pregnancies. This finding is like the outcome of a study in India where physically abused women were discovered to be almost twice as likely to experience foetal losses (Jejeeboy, 1998). The pathway through which domestic violence influences the decision to terminate pregnancy can be explain in terms of the psychological or financial preparedness of women experiencing domestic violence to care for a child. Women may consider a chaotic marriage marred by domestic violence as an unhealthy environment for raising children. Also, our definition of domestic violence includes sexual assault which is likely to prevent the use of contraceptives and this often result in unintended pregnancies. Women may choose to terminate such unintended pregnancies out of fear that the partner/husband may abuse/neglect the child. Hence, screening for domestic violence during antenatal care visits will be a vital intervention point to reduce the prevalence of terminated pregnancies and consequently, improve maternal health. This will involve increasing awareness of domestic violence among doctors, nurses, mid-wives and other health practitioners engaged in the provision of antenatal care. It is important that medical professionals be able to identify domestic violence unambiguously and decide on the appropriate care for pregnant women. That is, creating support network for pregnant women experiencing domestic violence will be crucial in improving both maternal and child health.

These study findings are subject to several limitations. First, it is a cross-sectional design; hence establishing causality will require robust econometric techniques. However, our approach to analysing domestic violence is within the framework of intrahousehold bargaining power dynamics. This approach will broaden the discussion on the associations between domestic violence and its identified predictors. Second, there is the issue of reporting bias. The information on domestic violence was based on self-reported data provided by the women and this introduces misclassification bias. However, since the burden of domestic violence falls more on the woman, being the source of information on domestic violence, we consider the self-report data to be a rough reflection of the actual experience of women.

\subsection{Conclusion}

In this study, we identify the determinants of domestic violence in Nigeria within the context of marriage using the DHS data. We defined domestic violence to include physical violence, emotional violence and sexual violence. The predictors of domestic violence were investigated among a list of individual and couple characteristics contain in the dataset. We found that women, who are poor, with low levels of education, reside in rural areas, having husbands who drink, and own lands are likely to experience domestic violence. In addition, women that are employed, having husbands that are employed, and have marital capital have higher odds of domestic violence. Next, we examined the impact of domestic violence on maternal health outcome-terminated pregnancies. We discovered that women that have experienced domestic violence are more likely to terminate pregnancies compared to women with no experience of domestic violence. In general, our findings suggest the importance of understanding domestic violence in the context of the dynamics of marriage as defined by cultural structures and the strategies adopted by couples for their survival.

\section{REFERENCES}

Adjah, O. \& Agbemafle, E.S (2016). Determinants of domestic violence against women in Ghana. BMC Public 


\section{Health, 16368}

Agarwal, B. (1997). Bargaining and gender relations: Within and beyond the household. Feminist Economics, 3(1), $1-51$

Aizer, A. (2011). Poverty, violence, and health: The impact of domestic violence during pregnancy on newborn health. Journal of Human Resources 46 (3), 518-538

Ajala, T. (2017). Gender discrimination in land ownership and the alleviation of women's poverty in Nigeria: A Call for new equities. International Journal of Discrimination and the Law, 17(1), 51-66

Amy Farmer \& Jill Tiefenthaler (1997). An economic analysis of domestic violence. Review of Social Economy, $55(3), 337-358$

Atsiya, P. A., Atsiya, G. P \& Agubutu, S. A (2019). Land ownership, household bargaining power and child health outcomes: Evidence from the NDHS. Journal of Economics and Allied Research. 3(1).

Barnawi, F. H. (2017). Prevalence and risk factors of domestic violence against women attending a primary care centre in Riyadh, Saudi Arabia. Journal of Interpersonal Violence, 32(8), 1171-1186.

Bates, L., Schuler, S., Islam, F., \& Md. Khairul Islam. (2004). Socioeconomic factors and processes associated with domestic violence in Rural Bangladesh. International Family Planning Perspectives, 3 0(4), 190-199.

Bhattacharyya, M., Bedi, A. S. \& Chhachhi, A. (2011). Marital violence and women's employment and property status: Evidence from North Indian villages. World Development. 39 (9), 1676-1689

Boden, J.M, Fergusson, D.M., \& Horwood, L.J. (2012). Alcohol misuse and violent behaviour: Findings from a 30-year longitudinal study. Drug Alcohol Depend, 122(1-2), 135-41.

DeKeseredy, W.S. \& Schwartz, M.D. (2002). Theorizing public housing woman abuse as a function of economic exclusion and male peer support. Women's Health and Urban Life 1(2), 26-45.

Ellsberg, M.C., Pefia, R., Herrera, A., Liljestrand, J. \& Winkvist, A. (1999). Wife abuse among women of childbearing age in Nicaragua. American Journal of Public Health 89(2), 241-244.

Garcia-Moreno, C., Jansen, H., Ellsberg, M., Heise, L., \& Watts, C. (2006). Prevalence of intimate partner violence: Findings from the WHO multi-country study on women's health and domestic violence. Lancet 368,12601269.

Gebara, C. F., Ferri, C. P., Lourenco, L. M., Vieira, M., Bhona, F. M., \& Noto, A. R. (2015). patterns of domestic violence and alcohol consumption among women and the effectiveness of a brief intervention in a household setting: A protocol study. BMC Women's Health, 15, 78.

Goode, W. (1971). Force and violence in the family. Journal of Marriage and the Family, 33, 624-636.

Heise, L., Ellsberg, M. \& Gottemoeller, M. (2002). A global overview of gender-based violence. International Journal of Gynaecology and Obstetrics, 2002, 78(Suppl. 1): S5-S14

Hidrobo, M. \& Fernald, L. (2013). Cash transfers and domestic violence. Journal of Health Economics, 32(1), 304-319

Hindin, M.J., Kishor, S., \& Ansara, D.L. (2008) Intimate partner violence among couples in 10 DHS Countries: Predictors and health outcomes. DHS analytical Studies No. 18. Calverton, Maryland Macro International Inc., USA.

Hotaling, G. T., \& Sugarman, D. B. (1990). A risk marker analysis of assaulted wives. Journal of Family Violence, $5,1-13$.

ICRW (2002) Men, masculinity and domestic violence in India. Summary report of four Studies International Centre for Research on Women, Washington, DC

Ilika, A. (2005). Women's perception of partner violence in a rural Igbo community. African Journal of Reproductive Health, 9(3), 77-88.

Jejeebhoy, S. J (1998) Associations' between wife-beating, foetal and infant death: Impressions from a survey in rural India. Stud Fam Plan, 29 (3), 300-308.

Jewkes, R. (2002). Intimate partner violence: Causes and prevention. Lancet, 359(9315), 1423-1429.

Jewkes, R., Nduna, M., et al.K( 2008). Impact of Stepping Stones on incidence of HIV, HSV and sexual behaviour in rural South Africa: Cluster randomised controlled trial. British Medical Journal, 337, 506

Kritz, M. M \& Makinwa-Adebusoye, P. (2006) Ethnicity, work and family as determinants of women's decisionmaking autonomy in Nigeria. Population and Development Program.

Krug, E.G., Mercy, J.A., Dahlberg, L.L., \& Zwi, A.B. (2002). The World Report on violence and health. Lancet, 360(9339), 1083-8.

Leung, W. C \& et al. (2001) Pregnancy outcome following domestic violence in a Chinese community. International Journal of Gynaecology and Obstetrics, 72 (1), 79-80.

Levinson, D. (1989). Family violence in cross-cultural perspective. Newbury Park, CA: Sage Publication

Odimegwu, C.O. (2001). Couple formation and domestic violence among the Tiv of Benue state, Nigeria. In: International Colloquium Gender, Population and Development in Africa. Abidjan: UAPS, NED, ENSEA, IFORD.

Oyediran, K. A. \& Isiugo-Abaniher, U. (2005). Perceptions of Nigerian women on domestic violence. African 
Journal of Reproductive Health.

Panda, P. \& Agarwal, B. (2005). Marital violence, human development and women's property status in India. World Development, 33(5), 823-850.

Rapp, D., Zoch, B., Khan, M.M.H \& et al. (2012). Association between gap in spousal education and domestic violence in India and Bangladesh. BMC Public Health, 12,467.

Saltzman, L., Fanslow, J., McMahon, P., \& Shelley, G. (2002). Intimate partner violence surveillance: Uniform definitions and recommended data elements, Version 1.0. Atlanta, GA: Centre for Disease, Control and Prevention, National Centre for Injury Prevention and Control.

Schuler, S. R \& et al (1996). Credit programmes patriarchy and men's violence against women in rural Bangladesh. Social Science \& Medicine, 43(12), 1729- 1742.

Tumwesigye, N. M., Kyomuhendo, G.B., Greenfield, T. K \& Wanyenze R.K., (2012). Problem drinking and physical intimate partner violence against women: Evidence from a national survey in Uganda. BMC Public Health, 120, 399

Valladares, E. M et al. (2002). Physical partner abuse during pregnancy: A risk factor for low birth weight in Nicaragua. Obstetrics \& Gynaecology, 100(4),700-705

Vyas, S. \& Watts, C. (2009). How does economic empowerment affect women's risk of intimate partner violence in Low-and-Middle income countries? A systematic review of published evidence. Journal of International Development 21 (5), 577-602.

Wendt, S (2008) Constructions of local culture and impacts on domestic violence in an australian rural community. Journal of Rural Studies, 25(2), 175-184.

World Health Organization (2009). Violence prevention: The evidence. preventing violence by reducing the availability and harmful use of alcohol. World Health Organization, Geneva.

World Health Organization (2013) Violence against women: intimate partner and sexual violence against women (Fact Sheet No. 239). Retrieved from http://www.who.int/mediacentre/factsheets/fs239/enl

\section{Appendix}

Table 1. Summary Statistics

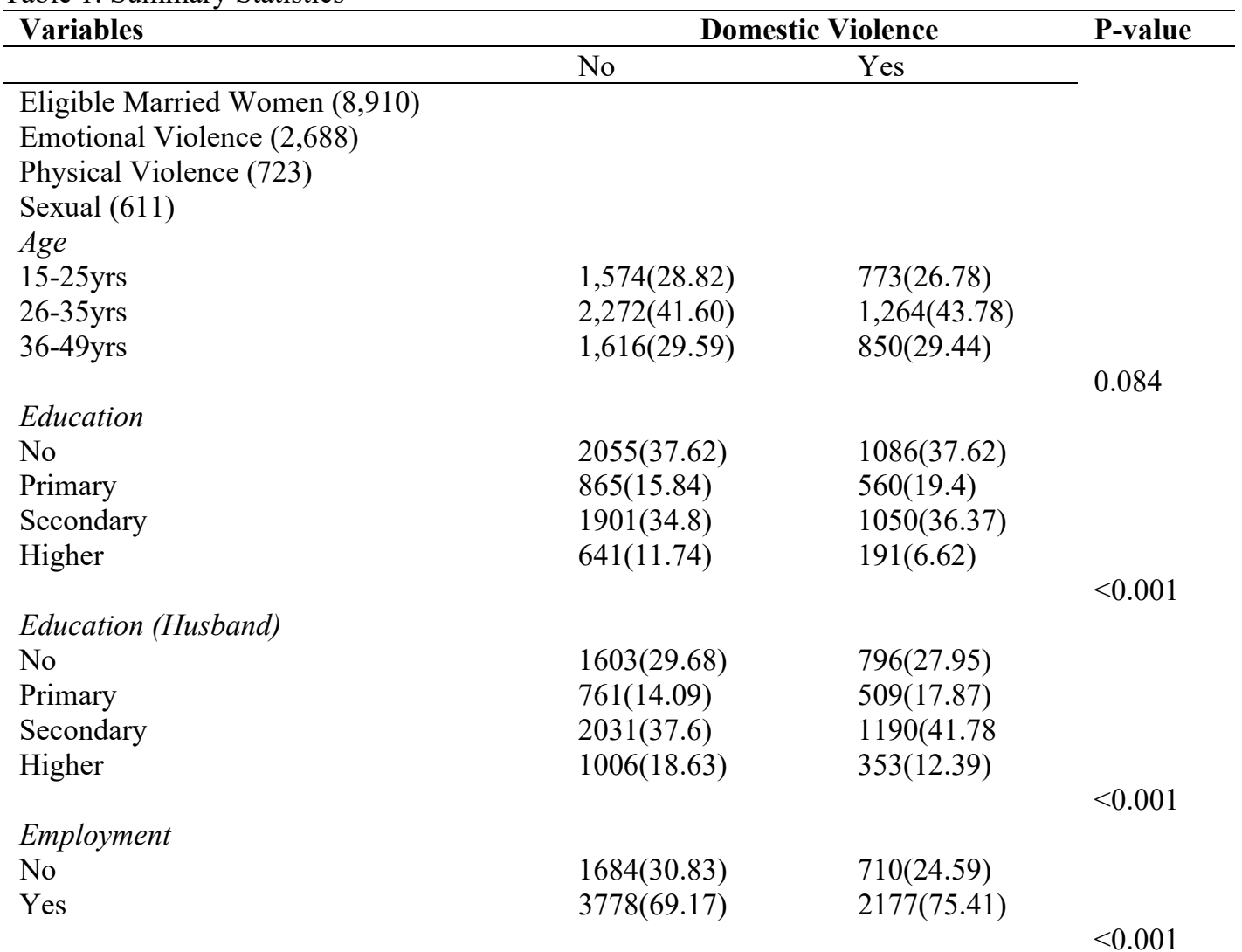




\begin{tabular}{|c|c|c|c|}
\hline \multicolumn{4}{|l|}{ Wealth Index } \\
\hline Poorest & $1026(18.78)$ & $619(21.44)$ & \\
\hline Poorer & $1024(18.75)$ & $628(21.75)$ & \\
\hline Middle & $1099(20.12)$ & $676(23.42)$ & \\
\hline Richer & $1134(20.76)$ & $578(20.02)$ & \\
\hline \multirow[t]{2}{*}{ Richest } & $1179(21.59)$ & $386(13.37)$ & \\
\hline & & & $<0.001$ \\
\hline Rural & $3183(58.28)$ & $1853(64.18)$ & \\
\hline \multirow[t]{2}{*}{ Urban } & $2279(41.72)$ & $1034(35.82)$ & \\
\hline & & & $<0.001$ \\
\hline \multicolumn{4}{|l|}{ Region } \\
\hline $\mathrm{NC}$ & $857(15.69)$ & $661(22.9)$ & \\
\hline $\mathrm{NE}$ & $738(13.51)$ & $681(23.59)$ & \\
\hline NW & $1489(27.26)$ & $460(15.93)$ & \\
\hline SE & $629(11.52)$ & $433(15)$ & \\
\hline SS & $568(10.4)$ & $404(13.99)$ & \\
\hline \multirow[t]{2}{*}{ SW } & $1181(21.62)$ & $248(8.59)$ & \\
\hline & & & $<0.001$ \\
\hline \multicolumn{4}{|l|}{ Religion } \\
\hline Islam & $2935(53.96)$ & $1268(43.95)$ & \\
\hline \multirow[t]{2}{*}{ Other } & $2504(46.04)$ & $1617(56.05)$ & \\
\hline & & & $<0.001$ \\
\hline \multicolumn{4}{|l|}{ Last Intercourse } \\
\hline One Week & $3472(63.57)$ & $1767(61.21)$ & \\
\hline Two Weeks & $507(9.28)$ & $283(9.8)$ & \\
\hline Three Weeks & $177(3.24)$ & $93(3.22)$ & \\
\hline \multirow[t]{2}{*}{ One Month Above } & $1306(23.91)$ & $744(25.77)$ & \\
\hline & & & 0.181 \\
\hline \multicolumn{4}{|l|}{ Alcohol (Husband) } \\
\hline No & $4509(82.55)$ & $1,824(63.18)$ & \\
\hline \multirow[t]{2}{*}{ Yes } & $953(17.45)$ & $1063(36.82)$ & \\
\hline & & & $<0.001$ \\
\hline \multicolumn{4}{|l|}{ Employ (Husband) } \\
\hline Unemployed & $201(3.71)$ & $50(2)$ & \\
\hline Employed & $3346(61.72)$ & $1589(55.29)$ & \\
\hline \multirow[t]{2}{*}{ Agric-Employ } & $1874(34.57)$ & $1235(42.97)$ & \\
\hline & & & $<0.001$ \\
\hline \multicolumn{4}{|l|}{ Age (Husband) } \\
\hline $15-35$ years & $2001(36.63)$ & $1053(36.47)$ & \\
\hline 36-55years & $2879(52.71)$ & $1558(53.97)$ & \\
\hline 56-75years & $566(10.36)$ & $269(9.32)$ & \\
\hline \multirow[t]{2}{*}{ 76-95years } & $16(0.29)$ & $7(0.24)$ & \\
\hline & & & 0.422 \\
\hline \multicolumn{4}{|l|}{ Land Ownership } \\
\hline No & $4691(85.88)$ & $2306(79.88)$ & \\
\hline Yes & $771(14.12)$ & $581(20.12)$ & \\
\hline
\end{tabular}


Table 2. Factors of Domestic Violence in Nigeria among currently Married Women.

\begin{tabular}{|c|c|c|c|}
\hline Variables & $\begin{array}{c}(1) \\
\text { Coeff }\end{array}$ & $\begin{array}{l}(2) \\
\text { OR }\end{array}$ & $\begin{array}{c}(3) \\
95 \% \mathrm{CI}\end{array}$ \\
\hline Poverty & $\begin{array}{c}-0.194 * * * \\
(0.489)\end{array}$ & $0.824 * * *$ & $(0.726-0.935)$ \\
\hline Alcohol & $\begin{array}{c}1.015^{* * *} \\
(0.428)\end{array}$ & $2.759 * * *$ & $(2.440-3.119)$ \\
\hline Employ (Woman) & $\begin{array}{c}0.147 * * \\
(0.452)\end{array}$ & $1.159 * *$ & $(1.034-1.299)$ \\
\hline Locality & $\begin{array}{c}-0.161 * * * \\
(0.489)\end{array}$ & $0.851 * * *$ & $(0.760-0.953)$ \\
\hline \multicolumn{4}{|l|}{ Education } \\
\hline No Education & $\begin{array}{c}\text { Ref } \\
(-)\end{array}$ & $\begin{array}{c}\text { Ref } \\
(-)\end{array}$ & $\begin{array}{c}\text { Ref } \\
(-)\end{array}$ \\
\hline Primary & $\begin{array}{c}-0.0423 \\
(0.376)\end{array}$ & 0.959 & $(0.823-1.116)$ \\
\hline Secondary & $\begin{array}{c}-0.139 * \\
(0.478)\end{array}$ & $0.871 *$ & $(0.747-1.015)$ \\
\hline Higher & $\begin{array}{c}-0.577 * * * \\
(0.299)\end{array}$ & $0.561 * * *$ & $(0.450-0.701)$ \\
\hline Num_Child & $\begin{array}{c}0.212 * * * \\
(0.547)\end{array}$ & $1.236 * * *$ & $(1.117-1.367)$ \\
\hline \multicolumn{4}{|l|}{ Age } \\
\hline $15-25$ years & $\begin{array}{l}\text { Ref } \\
(-)\end{array}$ & $\begin{array}{c}\text { Ref } \\
(-)\end{array}$ & $\begin{array}{c}\text { Ref } \\
(-)\end{array}$ \\
\hline $26-35$ years & $\begin{array}{c}-0.0259 \\
(0.494)\end{array}$ & 0.974 & $(0.859-1.105)$ \\
\hline $36-49$ years & $\begin{array}{c}-0.221 * * * \\
(0.456)\end{array}$ & $0.802 * * *$ & $(0.690-0.931)$ \\
\hline \multicolumn{4}{|l|}{ Employ (Husband) } \\
\hline Unemployed & $\begin{array}{c}\text { Ref } \\
(-)\end{array}$ & $\begin{array}{c}\text { Ref } \\
(-)\end{array}$ & $\begin{array}{c}\text { Ref } \\
(-)\end{array}$ \\
\hline Employed & $\begin{array}{c}0.588 * * * \\
(0.491)\end{array}$ & $1.800 * * *$ & $(1.299-2.493)$ \\
\hline Agric employed & $\begin{array}{c}0.729 * * * \\
(0.484)\end{array}$ & $2.073 * * *$ & $(1.494-2.875)$ \\
\hline Land Own & $\begin{array}{c}0.186^{* * * *} \\
(0.368)\end{array}$ & $1.204 * * *$ & $(1.058-1.370)$ \\
\hline Religion & $\begin{array}{l}0.124^{*} \\
(0.500)\end{array}$ & $1.132 *$ & $(0.994-1.290)$ \\
\hline Constant & $-1.621 * * *$ & $0.198 * * *$ & $(0.141-0.278)$ \\
\hline Observations & 8,270 & 8,270 & \\
\hline
\end{tabular}

sd in parentheses for coefficients

$* * * \mathrm{p}<0.01, * * \mathrm{p}<0.05, * \mathrm{p}<0.1$ 
Table 3. Factors of Domestic Violence controlling for Ethnicity

\begin{tabular}{|c|c|c|c|}
\hline Variables & $\begin{array}{c}(1) \\
\text { Coeff }\end{array}$ & $\begin{array}{l}(2) \\
\mathrm{OR} \\
\end{array}$ & $\begin{array}{c}(3) \\
95 \% \mathrm{CI} \\
\end{array}$ \\
\hline Poverty & $\begin{array}{c}-0.147 * * \\
(0.489)\end{array}$ & $0.864 * *$ & $(0.759-0.983)$ \\
\hline Alcohol & $\begin{array}{c}1.024 * * * \\
(0.428)\end{array}$ & $2.785 * * *$ & $(2.452-3.163)$ \\
\hline Employ (Women) & $\begin{array}{c}0.227 * * * \\
(0.452)\end{array}$ & $1.255^{* * *}$ & $(1.116-1.411)$ \\
\hline Locality & $\begin{array}{l}-0.0122 \\
(0.489)\end{array}$ & 0.988 & $(0.878-1.112)$ \\
\hline \multicolumn{4}{|l|}{ Education } \\
\hline No Education & $\begin{array}{l}\text { Ref } \\
(-)\end{array}$ & $\begin{array}{l}\text { Ref } \\
(-)\end{array}$ & $\begin{array}{c}\text { Ref } \\
(-)\end{array}$ \\
\hline Primary & $\begin{array}{c}-0.00536 \\
(0.376)\end{array}$ & 0.995 & $(0.850-1.164)$ \\
\hline Secondary & $\begin{array}{l}-0.0651 \\
(0.478)\end{array}$ & 0.937 & $(0.798-1.100)$ \\
\hline Higher & $\begin{array}{c}-0.532 * * * \\
(0.299)\end{array}$ & $0.588 * * *$ & $(0.468-0.738)$ \\
\hline Num_Child & $\begin{array}{c}0.195 * * * \\
(0.547)\end{array}$ & $1.215^{* * *}$ & $(1.097-1.346)$ \\
\hline \multicolumn{4}{|l|}{ Age } \\
\hline $15-25$ years & $\begin{array}{l}\text { Ref } \\
(-)\end{array}$ & $\begin{array}{l}\operatorname{Ref} \\
(-)\end{array}$ & $\begin{array}{c}\text { Ref } \\
(-)\end{array}$ \\
\hline $26-35$ years & $\begin{array}{c}-0.000662 \\
(0.494)\end{array}$ & 0.999 & $(0.880-1.135)$ \\
\hline $36-49$ years & $\begin{array}{c}-0.155^{* *} \\
(0.456)\end{array}$ & $0.857 * *$ & $(0.735-0.998)$ \\
\hline \multicolumn{4}{|l|}{ Employ (Husband) } \\
\hline Unemployed & $\begin{array}{l}\text { Ref } \\
(-)\end{array}$ & $\begin{array}{l}\text { Ref } \\
(-)\end{array}$ & $\begin{array}{c}\text { Ref } \\
(-)\end{array}$ \\
\hline Employed & $\begin{array}{c}0.637 * * * \\
(0.491)\end{array}$ & $1.890 * * *$ & $(1.361-2.627)$ \\
\hline Agric Employed & $\begin{array}{c}0.695^{* * *} \\
(0.484)\end{array}$ & $2.004 * * *$ & $(1.439-2.791)$ \\
\hline Land_Own & $\begin{array}{c}0.168^{* *} \\
(0.368)\end{array}$ & $1.183 * *$ & $(1.034-1.352)$ \\
\hline Religion & $\begin{array}{l}0.0163 \\
(0.500)\end{array}$ & 1.016 & $(0.867-1.191)$ \\
\hline \multicolumn{4}{|l|}{ Ethnicity } \\
\hline Others & $\begin{array}{l}\text { Ref } \\
(-)\end{array}$ & $\begin{array}{l}\text { Ref } \\
(-)\end{array}$ & $\begin{array}{c}\text { Ref } \\
(-)\end{array}$ \\
\hline Ekoi & $\begin{array}{c}-0.613 * \\
(0.0760)\end{array}$ & $0.542 *$ & $(0.286-1.027)$ \\
\hline Fulani & $\begin{array}{c}0.124 \\
(0.263)\end{array}$ & 1.132 & $(0.915-1.400)$ \\
\hline Hausa & $\begin{array}{c}-0.519 * * * \\
(0.430)\end{array}$ & $0.595 * * *$ & $(0.505-0.702)$ \\
\hline Ibibio & $\begin{array}{l}-0.272 \\
(0.131)\end{array}$ & 0.762 & $(0.528-1.097)$ \\
\hline Igala & $\begin{array}{c}0.352 \\
(0.103)\end{array}$ & 1.421 & $(0.903-2.237)$ \\
\hline Igbo & $\begin{array}{c}-0.519 * * * \\
(0.363)\end{array}$ & $0.595 * * *$ & $(0.502-0.705)$ \\
\hline Ijaw/Izon & $\begin{array}{l}-0.273^{*} \\
(0.163)\end{array}$ & $0.761^{*}$ & $(0.566-1.025)$ \\
\hline Kanuri/Beriberi & $\begin{array}{c}-0.594 * * * \\
(0.146)\end{array}$ & $0.552 * * *$ & $(0.382-0.798)$ \\
\hline
\end{tabular}




\begin{tabular}{lccc}
\hline & $(1)$ & $(2)$ & $(3)$ \\
Variables & Coeff & OR & $95 \%$ CI \\
\hline Tiv & -0.150 & 0.860 & $(0.633-1.170)$ \\
& $(0.156)$ & & $(0.312-0.443)$ \\
Yoruba & $-0.990^{* * *}$ & $0.372 * * *$ & $(0.168-0.354)$ \\
Constant & $(0.361)$ & & \\
Observations & $-1.412^{* * *}$ & $0.244 * * *$ & \\
\hline
\end{tabular}

sd in parentheses for coefficients

$* * * \mathrm{p}<0.01, * * \mathrm{p}<0.05, * \mathrm{p}<0.1$

Table 4. Domestic Violence and Terminated Pregnancies in Nigeria

\begin{tabular}{|c|c|c|c|}
\hline Variables & $\begin{array}{c}\text { (1) } \\
\text { Coeff (sd) }\end{array}$ & $\begin{array}{l}\text { (2) } \\
\text { OR }\end{array}$ & $\begin{array}{c}(3) \\
95 \% \mathrm{CI}\end{array}$ \\
\hline Violence & $\begin{array}{c}0.225^{* * *} \\
(0.476)\end{array}$ & $1.252 * * *$ & $(1.105-1.418)$ \\
\hline Health Autonomy & $\begin{array}{c}0.359 * * * \\
(0.450)\end{array}$ & $1.432 * * *$ & $(1.203-1.704)$ \\
\hline \multicolumn{4}{|l|}{ Education } \\
\hline No Education & $\begin{array}{l}\text { Ref } \\
(-)\end{array}$ & $\begin{array}{c}\operatorname{Ref} \\
(-)\end{array}$ & $\begin{array}{c}\operatorname{Ref} \\
(-)\end{array}$ \\
\hline Primary & $\begin{array}{c}-0.0600 \\
(0.376)\end{array}$ & 0.942 & $(0.785-1.129)$ \\
\hline Secondary & $\begin{array}{r}-0.0315 \\
(0.478)\end{array}$ & 0.969 & $(0.829-1.132)$ \\
\hline $\begin{array}{l}\text { Higher } \\
\text { Age }\end{array}$ & $\begin{array}{l}0.195^{*} \\
(0.300)\end{array}$ & $1.215^{*}$ & $(0.977-1.512)$ \\
\hline $15-25 \mathrm{yrs}$ & $\begin{array}{c}\text { Ref } \\
(-)\end{array}$ & $\begin{array}{c}\text { Ref } \\
(-)\end{array}$ & $\begin{array}{c}\text { Ref } \\
(-)\end{array}$ \\
\hline $26-35 \mathrm{yrs}$ & $\begin{array}{c}0.456^{* * *} \\
(0.494)\end{array}$ & $1.577 * * *$ & $(1.324-1.879)$ \\
\hline $36-49 y r s$ & $\begin{array}{c}0.583 * * * \\
(0.456)\end{array}$ & $1.792 * * *$ & $(1.478-2.173)$ \\
\hline Employment & $\begin{array}{l}-0.153^{*} \\
(0.452)\end{array}$ & $0.858^{*}$ & $(0.727-1.012)$ \\
\hline \multicolumn{4}{|l|}{ Parity } \\
\hline No Child & $\begin{array}{c}\text { Ref } \\
(-)\end{array}$ & $\begin{array}{c}\text { Ref } \\
(-)\end{array}$ & $\begin{array}{c}\text { Ref } \\
(-)\end{array}$ \\
\hline Parity1 & $\begin{array}{l}-0.227 \\
(0.346)\end{array}$ & 0.797 & $(0.585-1.087)$ \\
\hline Parity2 & $\begin{array}{c}-0.312 * * \\
(0.398)\end{array}$ & $0.732 * *$ & $(0.550-0.974)$ \\
\hline Locality & $\begin{array}{l}0.0395 \\
(0.489)\end{array}$ & 1.040 & $(0.911-1.188)$ \\
\hline \multicolumn{4}{|l|}{ Under-five } \\
\hline No Child & $\begin{array}{l}\text { Ref } \\
(-)\end{array}$ & $\begin{array}{l}\text { Ref } \\
(-)\end{array}$ & $\begin{array}{c}\text { Ref } \\
(-)\end{array}$ \\
\hline Four \& below & $\begin{array}{c}-0.251 * * * \\
(0.397)\end{array}$ & $0.778 * * *$ & $(0.660-0.917)$ \\
\hline Five -Nine & $\begin{array}{l}0.0720 \\
(0.111)\end{array}$ & 1.075 & $(0.635-1.819)$ \\
\hline Constant & $-1.853 * * *$ & $0.157 * * *$ & $(0.120-0.204)$ \\
\hline Observations & 8,331 & 8,331 & \\
\hline
\end{tabular}

